\title{
Pilhas de Combustível
}

\section{LUÍs ALCÁCER}

As células, que constituem as pilhas de combustível, convertem directamente energia química em energia eléctrica com rendimentos elevados e são pouco polventes. Contudo, para que a tecnologia das pilhas de combustível venha a ter uma comparticipação significativa no mercado de produção de energia, é necessário resolver muitos problemas relacionados com a escolha dos combustíveis e com os materiais de que são feitas. Neste artigo, faremos uma descrição do princípio de funcionamento e dos tipos de pilhas mais comuns, bem como algumas considerações sobre os materiais mais adequados e perspectivas de desenvolvimento.

\section{INTRODUÇÃO}

As questões relacionadas com a utilização e os custos de energia constituem preocupações tanto do cidadão comum como de instituições e governos de todo o mundo. Efeito de estufa, emissões de $\mathrm{CO}_{2}$, alterações climáticas, dependência das reservas de combustíveis fósseis são temas recorrentes dessas preocupações.

Cerca de $80 \%$ da produção de energia eléctrica vem de combustíveis fósseis e combustível nuclear, e grande parte da energia consumida em transportes tem origem no petróleo. As previsões do Conselho Mundial de Energia (World Energy Council) indicam que a procura de energia irá triplicar até 2050, à medida que a população mundial sobe a 8 a 9 mil milhões e os países em desenvolvimento elevam os seus padrões de consumo. Os combustíveis fósseis são, por definição, não renováveis e, por conseguinte, destinados a esgotar-se, forçando as economias a mudar, e gerando tensões geopolíticas. As emissões dos combustíveis fósseis e os resíduos do nuclear criam poluição atmosférica, das águas e do ar, e lixo tóxico. $O$ Painel Intergovernamental sobre mudanças climáticas das Nações Unidas (Intergovernamental Panel on Climate Changes, IPCC) chama a atenção para o facto de que essas emissões e resíduos causam mudanças significativas dos padrões climáticos que afectarão toda a humanidade nas próximas décadas.

A tomada de consciência dos problemas ambientais e das limitações relativas às fontes de energia estão a conduzir a uma profunda evolução no modo de encarar a sua produção e gestão. Embora seja previsível que os combustíveis fósseis e o nuclear continuem a ser as principais fontes de energia durante muitos anos, há uma urgência premente de desenvolvimento de soluções alternativas de produção e armazenamento de energia. A procura de tecnologias mais limpas, mais baratas, com instalações de menor dimensão, e mais eficientes tem levado a desenvolvimentos recentes, os quais quase sempre se situam na área da ciência e engenharia de materiais.

As esperanças, em tempo, depositadas nas energias renováveis são totalmente irrealistas e quando muito, elas poderão vir a representar uma contribuição máxima de uns $20 \%$ para a produção total de energia no mundo. As acções, apoios e incentivos dos governos, visando soluções imediatas, carecem de coerência e visão estratégica a longo prazo.

Se soluções há para estes problemas, elas passam necessariamente por i) implementação de uma gestão mais racional dos recursos energéticos (e.g. redução de consumos desnecessários, etc.); ii) mudança de paradigma para a energia usada em transportes; iii) maior recurso ao nu- clear; iv) diversificação da produção com inclusão da contribuição possível das energias renováveis.

O uso de um motor eléctrico silencioso, não poluente, com elevada eficiência pareceria ser a solução ideal para alguns desses problemas. Embora se pensasse inicialmente que o problema se resolveria com o uso de acumuladores para armazenar energia para veículos de tracção eléctrica, que seriam ligados à rede, uma análise aprofundada mostra que tal solução não é viável, em larga escala, devido a limitações na eficiência dos ciclos de carga e descarga, pelo número limitado de ciclos possíveis, e mais do que tudo, pela necessidade das lentas operações de carga e da sua dependência das centrais eléctricas.

Em face da promessa de produzir energia limpa com eficiências elevadas, as pilhas de combustível têm sido muitas vezes mencionadas nas televisões e nos jornais por todo o mundo nas últimas décadas especialmente depois de 1997. À luz do quadro actual de intensa investigação em procura de fontes alternativas de energia não poluente, estes dispositivos electroquímicos emergem como candidatos sérios para aplicações em veículos de transporte, em centrais de produção de energia e em fontes de alimentação para dispositivos electrónicos portáteis (e.g., telemóveis e computadores).

Embora a ideia de implementar uma economia de hidrogénio sugira um 
cenário optimista, a sua implementação enfrenta dificuldades técnicas enormes.

A tecnologia mais económica para produção de hidrogénio em larga escala é a partir do gás natural e produz quantidades consideráveis de gases poluentes. A acrescentar o problema do armazenamento que também não se afigura simples. A menos que haja um avanço significativo no que respeita aos processos de produção e armazenamento de hidrogénio, a ideia de uma economia de hidrogénio continua a ser um cenário pouco realista.

No que respeita a células de combustível, as que se afiguram mais viáveis comercialmente são as baseadas em combustíveis hidrocarbonetos ou metanol e etanol. De outro modo, as tecnologias das células de combustível serão limitadas a nichos de actividade restritos, para os quais o hidrogénio possa ser uma opção comercial, como em transportes urbanos. A escolha do combustível será de qualquer modo um factor decisivo na comercialização das pilhas de combustível e na sua penetração no mercado.

Apesar das atractivas características das tecnologias das pilhas de combustível, nomeadamente das eficiências de conversão de energia e dos benefícios ambientais a elas associados, o desenvolvimento de produtos industriais comercialmente viáveis tem sido difícil.

O desenvolvimento tecnológico nesta área é um desafio de natureza multidisciplinar, mas, tal como em todas as tecnologias de produção de energia, muitos dos problemas encontrados estão associados à inexistência de materiais apropriados ou processos de fabrico que viabilizem custos da energia por kWh competitivos com as tecnologias existentes.

Neste breve texto, faremos uma descrição do princípio de funcionamento das células de combustível, e das suas variedades, após o que analisaremos alguns dos aspectos mais relevantes relativamente aos materiais actualmente usados e suas características, bem como as perspectivas de desenvolvimentos futuros.

\section{Princípio de Funcionamento}

A célula de combustível, inventada em 1839 por Sir William Grove, tem como paradigma actual, a célula de $\mathrm{H}_{2} / \mathrm{O}_{2}$. É um dispositivo electroquímico que converte directamente energia química em energia eléctrica e calor. A reacção química global envolve a combinação de hidrogénio com oxigénio dando origem à formação de água.

As células de combustível são semeIhantes às baterias, sendo compostas por dois eléctrodos, o cátodo e o ânodo, normalmente porosos e revestidos por um catalisador, em geral, platina, e separados por um electrólito (Fig. 1).

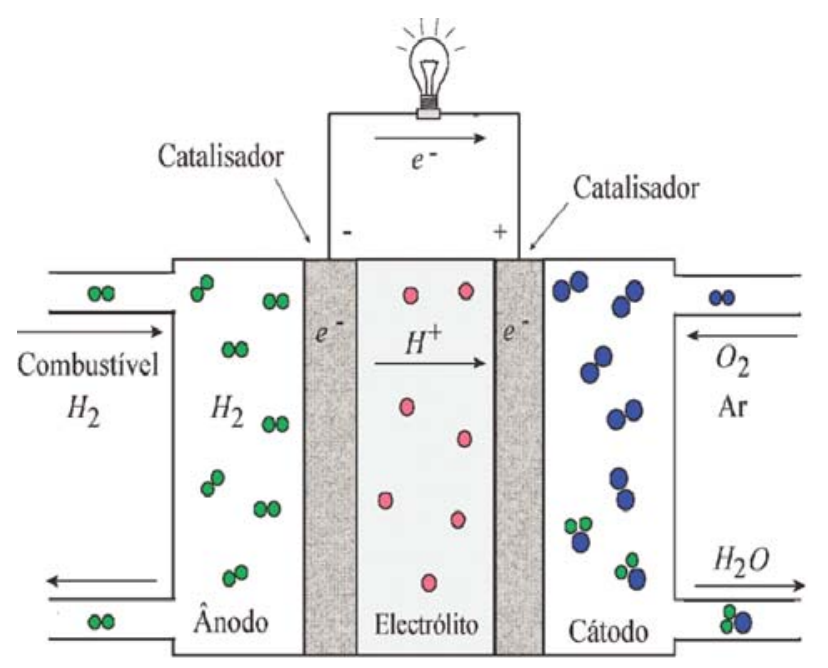

Figura 1 Esquema básico de funcionamento de uma célula de combustível

No ânodo, o combustível, tipicamente o hidrogénio molecular, é convertido em iões $\mathrm{H}^{+}$(protões) e electrões. Os electrões alimentam o circuito exterior, gerando trabalho (energia), e vão recombinar-se no cátodo com os protões que circularam através do electrólito, e com o oxigénio, aí presente, produzindo água. O electrólito, que pode ser uma solução líquida ou um sólido condutor iónico serve simultaneamente de separador entre os reagentes e isola os eléctrodos relativamente à condução de electrões, formando uma ponte salina entre o compartimento do ânodo e o do cátodo.

O cátodo, o ânodo e o electrólito constituem os elementos básicos de uma célula de combustível.

Na célula de $\mathrm{H}_{2} / \mathrm{O}_{2}$, as semi-reacções que ocorrem em cada um dos eléc- trodos e os respectivos potenciais de semi-reacção, são os seguintes:

No ânodo:

$\mathrm{H}_{2} \rightarrow 2 \mathrm{H}^{+}(\mathrm{aq})+2 \mathrm{e}^{-} \quad E_{1}{ }^{0}=0 \mathrm{~V}$

No cátodo:

$$
\begin{array}{r}
1 / 2 \mathrm{O}_{2}(\mathrm{~g})+2 \mathrm{H}^{+}(\mathrm{aq})+2 \mathrm{e}^{-} \rightarrow \mathrm{H}_{2} \mathrm{O}^{-}(\ell) \\
E_{2}^{0}=+1,23 \mathrm{~V}
\end{array}
$$

A reacção química global é portanto

$$
\mathrm{H}_{2}(\mathrm{~g})+1 / 2 \mathrm{O}_{2}(\mathrm{~g}) \rightarrow \mathrm{H}_{2} \mathrm{O}(\ell)
$$

implicando uma força electromotriz a $25{ }^{\circ} \mathrm{C}$ e nas condições padrão ( $p=1$ bar) de

$$
\text { f.e.m. }=E_{2}^{0}-E_{1}^{0}=1,23 \mathrm{~V}
$$

A conversão de energia química em energia eléctrica é directa. A energia de Gibbs, $\Delta G^{0}$ é totalmente convertida em energia eléctrica, sendo portanto $\Delta G^{0}=-n F E^{0}$, em que $n$ é o número de electrões envolvidos na reacção, $F$ é a constante de Faraday ( $F=96485$ C), que corresponde à carga eléctrica de uma mole de electrões, e $E^{0}$ a força electromotriz teórica. De facto, atendendo a que a energia de Gibbs de formação da água líquida é $\Delta_{\mathrm{f}} G^{0}\left[\mathrm{H}_{2} \mathrm{O}(\ell)\right]=-237,13 \mathrm{~kJ} / \mathrm{mol}$ vem $E^{0}=-\Delta G^{0} / n F=237130 /$ $/(2 \times 96485)=1,23 \mathrm{~V}$.

Uma pilha de combustível é um conjunto de células ligadas em série.

As pilhas de combustível não são máquinas térmicas, e, por conseguinte, não estão limitadas pela $2^{\mathrm{a}}$ lei da termodinâmica, podendo o seu rendi- 
mento ser muito maior (ver Caixa 2). Nas células de combustível, o rendimento pode atingir os $70 \%$ - o dobro do de um motor de combustão (máquina térmica). Além disso as pilhas de combustível são silenciosas.

Apesar de termodinamicamente espontânea, a combustão do hidrogénio nas células de combustível tem uma cinética complexa e requer o uso de um catalisador para vencer as barreiras de potencial que inviabilizam a reacção.

\section{Tipos de Pilhas de Combustível}

Embora todas baseadas no mesmo princípio geral - as pilhas de combustível são agrupamentos de células electroquímicas onde ocorre a oxidação de um combustível - existem vários tipos de células de combustível, usualmente designadas pelo nome do electrólito que utilizam. As principais características dos diferentes tipos de células estão resumidas na Tabela 1.
$\mathrm{CO}$, e requerem catalisadores de metais preciosos $(\mathrm{Pt}, \mathrm{Pd})$. Têm, por isso, custos mais elevados.

\section{Células de Combustível Alcalinas ou} afC (acrónimo de Alcaline Fuel Cell)

As células de combustível alcalinas usam como electrólito uma solução concentrada de hidróxido de potássio, $\mathrm{KOH}$, de $85 \%$ em peso, no regime de temperaturas elevadas (da ordem dos $250{ }^{\circ} \mathrm{C}$ ) e com concentrações entre 35 e $50 \%$ em peso, para regimes de temperatura inferiores a $120^{\circ} \mathrm{C}$.

No regime de baixas temperaturas, as velocidades de reacção são baixas, pelo que devem ser usados eléctrodos porosos impregnados com platina e recorrendo a pressões elevadas. Uma das vantagens deste tipo de células é a possibilidade do uso de catalisadores à base de metais não preciosos, como o níquel, o que garante custos mais reduzidos, com a vantagem adicional do baixo custo do electrólito.
No programa Apollo da NASA foram usadas células deste tipo a funcionar à temperatura de $250^{\circ} \mathrm{C}$ com solução de $\mathrm{KOH}$ de $85 \%$ peso, as quais forneciam água à tripulação, tendo este tipo de células sido também usado nos vaivéns espaciais (space shuttles).

O êxito da utilização de células AFC em veículos espaciais deve-se à excelente cinética dos eléctrodos quando funcionam com hidrogénio e oxigénio puros. No entanto, devido aos custos elevados do combustível, para serem competitivas em aplicações terrestres, torna-se necessário substituir o hidrogénio por combustíveis mais baratos à base de hidrocarbonetos ou álcool o que coloca severos problemas relacionados com os materiais das células e com as tecnologias de processamento dos combustíveis. Apesar de mais de três décadas de investigação e desenvolvimento sobre este tipo de células para aplicações em autocarros, primeiro pela Elenco, que acabou por vender os direitos técnicos à Zevco, é

Tabela 1 Resumo dos diferentes tipos de células de combustível

\begin{tabular}{|c|c|c|c|c|c|}
\hline & \multicolumn{5}{|c|}{ Tipos de células } \\
\hline & $\begin{array}{c}\text { Alcalinas } \\
\text { AFC } \\
\text { (Alkaline Fuel Cell) }\end{array}$ & $\begin{array}{c}\text { de Electrólito Polimérico } \\
\text { PEFC/PEM } \\
\text { (Polymer Electrolyte Fuel } \\
\text { Cell) }\end{array}$ & $\begin{array}{c}\text { de Ácido Fosfórico } \\
\text { PAFC } \\
\text { (Phosphoric acid Fuel } \\
\text { Cell) }\end{array}$ & $\begin{array}{l}\text { de Carbonatos Fundidos } \\
\text { MCFC } \\
\text { (Molten carbonate Fuel } \\
\text { Cell) }\end{array}$ & $\begin{array}{c}\text { de Óxido Sólido } \\
\text { SOFC } \\
\text { (Solid Oxide Fuel Cell) }\end{array}$ \\
\hline Combustível & $\mathrm{H}_{2}$ puro & $\mathrm{H}_{2}$ puro & $\mathrm{H}_{2}$ & $\mathrm{CH}_{4}, \mathrm{H}_{2}, \mathrm{CO}$ & $\mathrm{CH}_{4}, \mathrm{H}_{2}, \mathrm{CO}$ \\
\hline Oxidante & $\mathrm{ar}+\mathrm{H}_{2} \mathrm{O}\left(\mathrm{s} / \mathrm{CO}_{2}\right)$ & $\operatorname{ar}(\mathrm{s} / \mathrm{CO})$ & $\operatorname{ar}(\mathrm{s} / \mathrm{CO})$ & $\mathrm{ar}+\mathrm{CO}_{2}$ & ar \\
\hline Electrólito & $\mathrm{KOH}$ & Membrana de polímero & Ácido fosfórico & $\begin{array}{l}\text { carbonatos de Li e K } \\
\text { fundidos }\end{array}$ & Óxidos de $\mathrm{Y}$ e $\mathrm{Zr}$ \\
\hline lão condutor & $\mathrm{OH}^{-}$ & $\mathrm{H}^{+}$ & $\mathrm{H}^{+}$ & $\mathrm{CO}_{3}^{2-}$ & $\mathrm{O}^{2-}$ \\
\hline $\begin{array}{l}\text { Temperatura de } \\
\text { funcionamento } /{ }^{\circ} \mathrm{C}\end{array}$ & $60-90$ & $70-90$ & 200 & $600-650$ & $800-1000$ \\
\hline $\begin{array}{l}\text { Rendimento Eléctrico } \\
/ \%\end{array}$ & $55-60$ & $35-45$ & $35-45$ & $45-55$ & $45-55$ \\
\hline Dimensão típica & $<7 \mathrm{~kW}$ & $5-250 \mathrm{~kW}$ & $200 \mathrm{~kW}$ & $2-3 \mathrm{MW}$ & $\begin{array}{l}\text { Tubular: } 100-5000 \mathrm{~kW} \\
\text { Planar: } 50-100 \mathrm{~kW}\end{array}$ \\
\hline
\end{tabular}

As células do tipo AFC, PEFC e PAFC são consideradas células de baixa e média temperatura, enquanto que as outras são de alta temperatura. As piIhas de alta temperatura não necessitam de catalisadores de metais preciosos, pois não são danificadas pelo CO. As de baixa e média temperatura, têm um processamento do combustível complexo, são mais sensíveis ao
As reacções associadas a este tipo de célula são as seguintes:

\section{Ânodo:}

$\mathrm{H}_{2}(\mathrm{~g})+2 \mathrm{OH}^{-}(\mathrm{aq}) \rightarrow 2 \mathrm{H}_{2} \mathrm{O}(\ell)+2 \mathrm{e}^{-}$

\section{Cátodo:}

$1 / 2 \mathrm{O}_{2}(\mathrm{~g})+\mathrm{H}_{2} \mathrm{O}(\ell)+2 \mathrm{e}^{-} \rightarrow 2 \mathrm{OH}^{-}(\mathrm{aq})$ quase certo que a penetração das piIhas AFC no mercado será pequena.

2. Células de Combustível de membraNA de Polímero OU PEMFC (aCRÓNIMO de Polymer Electrolyte Membrane Fuel CELL)

Nas células de combustível de membrana de polímero, também chamadas 
de membrana de permuta protónica, ou de electrólito polimérico, o electrólito é uma membrana de permuta iónica, ou polímero condutor iónico. Um dos materiais de membrana mais comuns é o Nafion, que é um copolímero derivado do tetrafluoroetileno, mais conhecido por Teflon (Esquema 1).

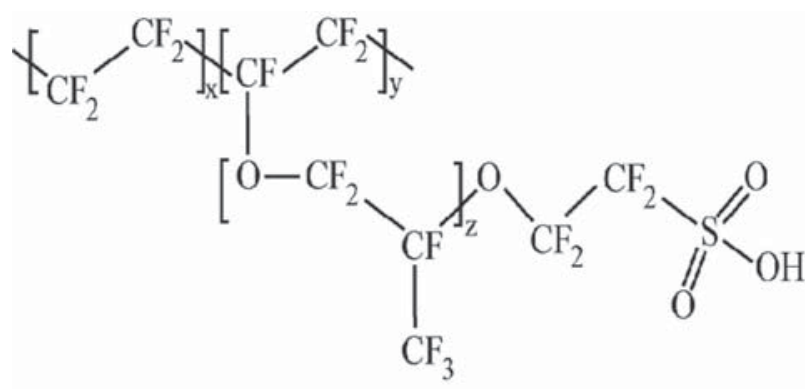

Esquema 1 Estrutura molecular do NAFION

Os protões gerados no ânodo, a partir do hidrogénio, por acção do catalisador, circulam até ao cátodo, onde se combinam com o oxigénio e com os electrões para dar água, o único líquido presente na célula. A presença de água é essencial para o funcionamento da célula pois a membrana tem de ser mantida hidratada para ser condutora de protões. As células funcionam a temperaturas inferiores aos $100{ }^{\circ} \mathrm{C}$ para evitar a deterioração do Nafion, o que implica velocidades de reacção reduzidas, necessitando, por isso, a utilização de catalisadores e eléctrodos sofisticados. O catalisador utilizado é a platina, o que, mesmo sendo possível usar em muito pequenas quantidades, representa uma parte considerável do custo total da célula.

Este tipo de célula requer hidrogénio de elevada pureza, só sendo possível usar combustíveis alternativos, como o metanol, o etanol, o metano ou o propano, desde que previamente convertidos em hidrogénio.

As células de membrana de polímero têm rendimentos elevados, emissões reduzidas e arranque rápido. Têm as vantagens de ser leves, e pouco volumosas quando comparadas com outras células de combustível. Os eléctrodos são de carbono poroso contendo o catalisador de platina sob a forma de pequenas partículas. $\mathrm{O}$ catalisador de platina é no entanto muito sensível a envenenamento pelo $\mathrm{CO}$, o que implica reactores adicionais para reduzir o $\mathrm{CO}$ no gás combustível de alimentação, se o hidrogénio for ob- tido a partir de um álcool ou de um hidrocarboneto. Os catalisadores de platina/ruténio, actualmente em desenvolvimento, são mais resistentes ao CO.

Estas pilhas são usadas sobretudo para aplicações em transportes e

aplicações estacionárias sendo particularmente atractivas para veículos de passageiros como carros e autocarros, devido à sua baixa razão potência-peso, e tempo de arranque rápido. As reacções associadas a este tipo de célula são as seguintes:

\section{Ânodo:}

$\mathrm{H}_{2}(\mathrm{~g}) \rightarrow 2 \mathrm{H}^{+}(\mathrm{aq})+2 \mathrm{e}^{-}$

\section{Cátodo:}

$1 / 2 \mathrm{O}_{2}(\mathrm{~g})+2 \mathrm{H}^{+}(\mathrm{aq})+2 \mathrm{e}^{-} \rightarrow \mathrm{H}_{2} \mathrm{O}(\ell)$

\section{Reacção global:}

$\mathrm{H}_{2}(\mathrm{~g})+1 / 2 \mathrm{O}_{2}(\mathrm{~g}) \rightarrow \mathrm{H}_{2} \mathrm{O}(\ell)$

Na Fig. 2 representa-se um esquema de uma pilha de combustível do tipo PEMFC, onde se destacam as membranas e outra das componentes das pilhas, as placas bipolares.
As placas bipolares são placas condutoras que, numa pilha, actuam como ânodo para uma célula e como cátodo para a célula seguinte.

Células de combustível de alimentação directa de metanol

Estas células são variantes das células de combustível de membrana de polímero que usam metanol como combustível. Têm como vantagem o facto de usar um combustível líquido, de fácil armazenamento e transporte. O principal problema destas células é o sobrepotencial electroquímico no ânodo, que as torna menos eficientes. Um outro problema é o facto de o metanol se difundir através da membrana.

Este tipo de células é particularmente atractivo para utilização como fonte de alimentação de equipamentos electrónicos portáteis, como computadores e telemóveis, bem como em veículos eléctricos. O uso de etanol em vez de metanol constitui uma alternativa interessante, em desenvolvimento. As reacções associadas a este tipo de célula são as seguintes:

\section{No ânodo:}

$\mathrm{CH}_{3} \mathrm{OH}(\mathrm{aq})+\mathrm{H}_{2} \mathrm{O}(\ell) \rightarrow \mathrm{CO}_{2}(\mathrm{~g})+6 \mathrm{e}^{-+}$ $+6 \mathrm{H}^{+}(\mathrm{aq})$

\section{No cátodo:}

$6 \mathrm{H}^{+}(\mathrm{aq})+6 \mathrm{e}^{-+}+3 / 2 \mathrm{O}_{2}(\mathrm{~g}) \rightarrow$

$\rightarrow 3 \mathrm{H}_{2} \mathrm{O}(\ell)$

\section{Reacção global:}

$\mathrm{CH}_{3} \mathrm{OH}(\mathrm{aq})+3 / 2 \mathrm{O}_{2}(\mathrm{~g}) \rightarrow 2 \mathrm{H}_{2} \mathrm{O}(\ell)+$ $+\mathrm{CO}_{2}(\mathrm{~g})$

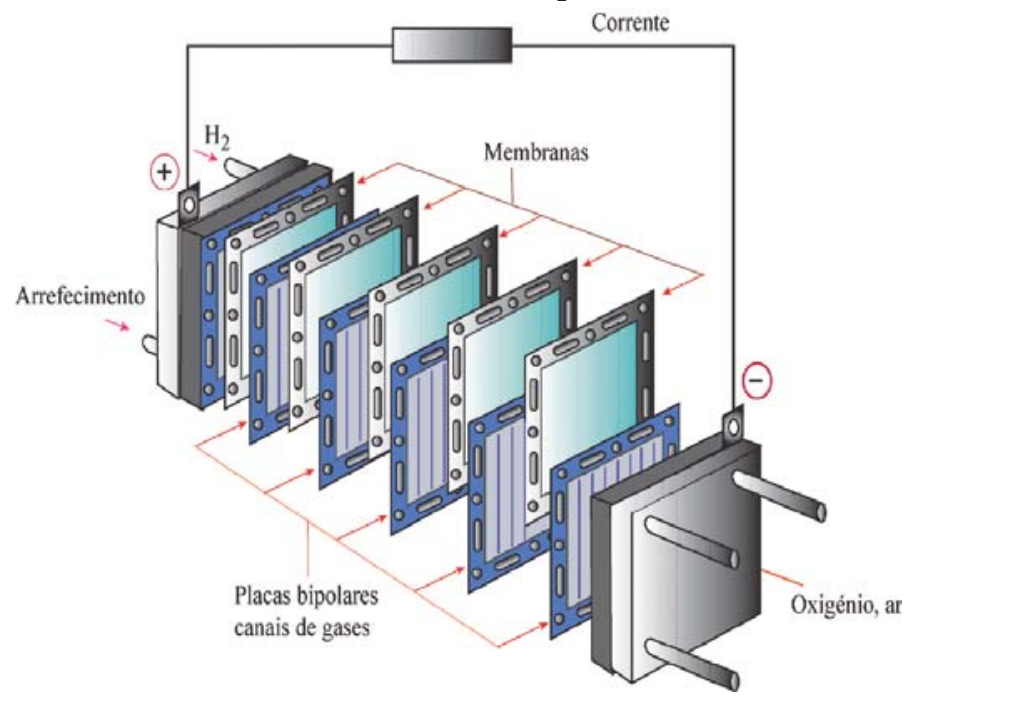

Figura 2 Esquema de uma pilha de combustível do tipo PEMFC, onde se destacam as membranas e as placas bipolares 
3. Células de Combustível de Ácido FosfórICO OU PAFC (ACRÓNIMO dE PHOSPHOric Acid Fuel Cell)

Nas células de combustível de ácido fosfórico, o electrólito é o ácido fosfórico a $100 \%$, e a temperatura de funcionamento é entre os $160^{\circ} \mathrm{C}$ e os $220^{\circ} \mathrm{C}$. A necessidade de temperaturas elevadas advém do facto que o ácido fosfórico é mau condutor iónico a baixa temperatura, sendo o envenenamento do catalisador de platina pelo CO no ânodo mais severo.

O ácido fosfórico é estável a alta temperatura, podendo as células funcionar com eficiência à temperatura de $220{ }^{\circ} \mathrm{C}$. Outra vantagem do uso de ácido concentrado reside na redução da pressão de vapor da água facilitando a sua gestão na célula. Atendendo a que o ácido fosfórico é muito corrosivo, o material do contentor tem de ser um material resistente à corrosão, como o carboneto de silício. O catalisador em ambos os eléctrodos é a platina.

Como em outros tipos de célula, o problema do armazenamento do hidrogénio pode ser resolvido recorrendo a combustíveis alternativos como o metano, que é convertido (em reformadores) em hidrogénio e $\mathrm{CO}_{2}$, implicando contudo custos e complexidade dos sistemas adicionais.

Este tipo de células é, apesar de tudo, de funcionamento simples, seguro e com baixos custos de manutenção, podendo funcionar em contínuo durante anos, sem necessidade de intervenção humana. Tendo sido o primeiro tipo de células a ser comercializado, têm uma vasta gama de aplicações, nomeadamente sob a forma de unidades de $200 \mathrm{~kW}$ (produzidas pela "International Fuel Cells Corporation") estando instaladas cerca de 200 unidades em todo o mundo, com excelente desempenho. O futuro deste tipo de células parece, no entanto estar comprometido, na medida em que os fabricantes não têm conseguido reduzir os custos de investimento abaixo dos $2000 €$ por kW, como originalmente programado. Pensa-se que para uma boa penetração nos mercados será necessário reduzir os custos até cerca de $700 €$ por kW os quais deve- rão baixar até cerca dos $350 €$ com o aumento do volume de produção.

As reacções associadas a este tipo de célula são as seguintes:

\section{Ânodo:}

$\mathrm{H}_{2}(\mathrm{~g}) \rightarrow 2 \mathrm{H}^{+}(\mathrm{aq})+2 \mathrm{e}^{-}$

\section{Cátodo:}

$1 / 2 \mathrm{O}_{2}(\mathrm{~g})+2 \mathrm{H}^{+}(\mathrm{aq})+2 \mathrm{e}^{-} \rightarrow \mathrm{H}_{2} \mathrm{O}(\ell)$

4. Células de Combustível de Carbonatos Fundidos (MCFC, de Molten Carbonate Fuel Cell)

Nas células de combustível de carbonatos fundidos, o electrólito é uma mistura de carbonatos de lítio, sódio e potássio, $\mathrm{Li} / \mathrm{Na} / \mathrm{KCO}_{3}$ mais comummente nas proporções $60 \%, 20 \%$, $20 \%$, respectivamente, incorporado numa matriz de $\gamma-\mathrm{LiAlO}_{2}$ e $\mathrm{Al}_{2} \mathrm{O}_{3}$. Os materiais do ânodo e do cátodo são, respectivamente, ligas de níquel-crómio e óxido de níquel dopado com lítio, sendo as placas bipolares de aço inoxidável. Estas células funcionam entre os $600^{\circ} \mathrm{C}$ e os $700^{\circ} \mathrm{C}$, temperaturas às quais a mistura é altamente condutora de iões carbonato. Nesta gama de temperaturas, é possível utilizar níquel como catalisador no ânodo e óxido de níquel no cátodo, baixando consideravelmente os custos de investimento. Pode ainda ser usado o gás natural sem necessidade de reformadores. Uma desvantagem é que a mistura de electrólitos de lítio, potássio e sódio, a alta temperatura, é extremamente corrosiva.

As reacções associadas a este tipo de célula são as seguintes:

\section{Ânodo:}

$\mathrm{H}_{2}(\mathrm{~g})+\mathrm{CO}_{3}^{2-} \rightarrow 2 \mathrm{H}_{2} \mathrm{O}(\mathrm{g})+\mathrm{CO}_{2}(\mathrm{~g})+$ $+2 \mathrm{e}^{-}$

\section{Cátodo:}

$1 / 2 \mathrm{O}_{2}(\mathrm{~g})+\mathrm{CO}_{2}(\mathrm{~g})+2 \mathrm{e}^{-} \rightarrow \mathrm{CO}_{3}{ }^{2-}$

5. Células de Combustível de Óxido SóLIDO OU SOFC (aCRóNIMO DE Solid OXIDE Fuel Cell)

O electrólito utilizado neste tipo de células é um óxido sólido, cerâmico, usualmente a ítria, $\mathrm{Y}_{2} \mathrm{O}_{3}$, estabilizada em zircónia, $\mathrm{ZrO}_{2}$ (YSZ), que na gama de temperaturas de funcionamento da célula, ou seja entre os 600 e os $1000^{\circ} \mathrm{C}$, é um excelente condutor iónico de $\mathrm{O}^{2-}$, iões que são assim facilmente transportados do cátodo para o ânodo.

Pelo facto de funcionar a alta temperatura, podem utilizar metano ou gás natural $\left(\mathrm{CH}_{4}, \mathrm{H}_{2}, \mathrm{CO}\right)$ directamente, sem ser necessária uma unidade reformadora.

É, no entanto, necessário um pré-aquecimento do combustível e do ar, bem como um sistema de arrefecimento, o que implica custos de investimento adicionais. O electrólito é sólido, mesmo a temperaturas de funcionamento da ordem dos $1000{ }^{\circ} \mathrm{C}$. Em geral, o material do ânodo é Co$\mathrm{ZrO}_{2}$ e o do cátodo $\mathrm{Sr}-\mathrm{LaMnO}_{3}$.

As reacções associadas a este tipo de célula são as seguintes:

\section{Ânodo:}

$\mathrm{H}_{2}(\mathrm{~g})+\mathrm{O}^{2-} \rightarrow \mathrm{H}_{2} \mathrm{O}(\mathrm{g})+2 \mathrm{e}^{-}$

\section{Cátodo:}

$1 / 2 \mathrm{O}_{2}(\mathrm{~g})+2 \mathrm{e}^{-} \rightarrow \mathrm{O}^{2-}$

\section{Materiais para Pilhas de Combustível}

A escolha dos materiais a usar em tecnologias de fabrico das pilhas de combustível que potencializem a sua competitividade como fonte alternativa de energia, envolve enorme complexidade e será eventualmente específica de cada produto e aplicação particulares.

É contudo possível tecer algumas considerações gerais sobre os materiais a integrar em pilhas de combustível.

São muitos os parâmetros que determinam as características das pilhas de combustível, nomeadamente a densidade de energia (em $\mathrm{kWh} / \mathrm{kg}$, ou em $\mathrm{kWh} / \mathrm{m}^{3}$ ), a densidade de potência (em $\mathrm{kW} / \mathrm{kg}$ ou em $\mathrm{kW} / \mathrm{m}^{3}$ ), o rendimento ou eficiência energética, e outros.

Do ponto de vista das especificações dos materiais a integrar nas pilhas de combustível, um dos parâmetros mais utilizados é a resistência específica ou ASR (do acrónimo combined area specific resistance), que se define na caixa 1. 


\section{Caixa 1}

\section{Resistência específica ou ASR}

Do ponto de vista da avaliação económica e das especificações dos materiais a integrar nas pilhas de combustível, um dos parâmetros mais utilizados é a resistência específica ou ASR (do acrónimo combined area specific resistance), que pode ser definida do seguinte modo.

Uma célula de combustível pode ser encarada como uma "caixa preta" na qual entra, de um lado, hidrogénio e, do outro, oxigénio (ar), e sai electricidade e gases de escape.

A ASR é definida como

$$
\text { ASR }=\frac{\text { f. e. } m \cdot-V}{\mathrm{I}} \quad \text { (expressa em } \Omega \mathrm{m}^{2} \text { ou } \Omega \mathrm{cm}^{2} \text { ) }
$$

em que f. e. $m$. é a força electromotriz e $V$ é a tensão da célula para a densidade de corrente I (expressa em $\mathrm{A} \mathrm{m}^{-2}$ ou $A\left(\mathrm{~cm}^{-2}\right.$ ). A tensão da célula $V$ deve ser medida independentemente dos cabos que transportam a corrente. $O$ parâmetro ASR é a soma de vários termos, nomeadamente, a resistência óhmica (devida ao electrólito, eléctrodos e colectores de corrente), a resitência de polarização dos eléctrodos, devida aos processos electroquímicos que ocorrem nas superfícies dos eléctrodos, nos materiais de eléctrodo e nas interfaces eléctrodo/electrólito, uma contribuição devida à difusão em fase gasosa e processos de oxidação do combustível (e.g., hidrogénio) e de redução do comburente (e.g., oxigénio), sendo as duas últimas contribuições as dominantes.

Para assegurar densidades de potência da ordem de $1 \mathrm{~kW} / \mathrm{kg}$ em geral mencionadas como as metas para aplicações em transportes, os valores de ASR devem ser da ordem de $0,1 \Omega \mathrm{cm}^{2}$, embora valores de $0,5 \Omega \mathrm{cm}^{2}$ já sejam considerados aceitáveis para a maioria das aplicações.

\section{Caixa 2}

\section{Eficiência das células de combustivel}

Para avaliar a eficiência das células de combustível deverá ser utilizado, não o rendimento termodinâmico, mas sim, o rendimento real ou efectivo. Este apenas iguala o rendimento termodinâmico ou ideal, se a tensão em circuito aberto coincidir com a força electromotriz teórica, $\mathrm{E}^{0}$, e se a tensão nos terminais da pilha não variar com a carga.

O rendimento de uma célula de combustível é dado pela expressão

$$
\eta=\eta_{\mathrm{g}} \cdot \eta_{v} \cdot \alpha
$$

em que $\eta_{g}$ é o rendimento de Gibbs, $\eta_{v}$ o rendimento de tensão e $\alpha$ a fraç̧ão de combustível utilizado.

$$
\begin{gathered}
\eta_{g}=\frac{\Delta G}{\Delta H}=-\frac{n F E_{0}}{\Delta H} \\
\eta_{v}=\frac{E}{E_{0}}=\frac{E_{0}-\mathbb{R}_{c}}{E_{0}}
\end{gathered}
$$

em que $E_{0}$ é a tensão em circuito aberto e $\Delta H$ é a entalpia (calor) de reaç̧ão global da célula. Assim,

$$
\eta=-\frac{n F\left(E_{0}-R_{c}\right)}{\Delta H} \alpha
$$

$R_{c}$ é a resistência específica (combined area specific resistance, ASR), em $\Omega \mathrm{m}^{2}$ ou $\Omega \mathrm{cm}^{2}$ das componentes da célula (ânodo, cátodo e electrólito). 
Uma condição essencial para o bom funcionamento de uma célula de combustível é o facto de que o electrólito, os reagentes gasosos, o catalisador e o colector de corrente têm de ser levados a um contacto íntimo numa região do espaço a que podemos chamar a interface tripla (triple-phaseboundary interface) na qual estão em geral presentes três fases: o electrólito (em geral uma solução liquida), os gases, combustível e comburente, e os eléctrodos. Isso implica que os eléctrodos sejam de material poroso, recoberto com nanopartículas de platina (catalisador) que assim podem estar em contacto com o electrólito. Certos materiais hidrofóbicos como o Teflon são de grande utilidade no fabrico das estruturas porosas para a difusão dos gases. Algumas das componentes que asseguram o percurso dos electrões são metálicas ou de grafite em pó ou mesmo de papel coberto de um dos lados com tintas condutoras, e para reduzir o parâmetro ASR dos eléctrodos incorporam-se redes metálicas nas suas estruturas. Nos anos de 1960, foram obtidos aumentos consideráveis da eficiência depositando nos eléctrodos pequenos cristais de catalisador de platina ou de ligas de platina, com dimensões da ordem do nanómetro, em pós de grafite ou papel, sendo esta provavelmente a primeira vez que foram concebidas e fabricadas nanoestruturas, o que, de certo modo, justifica a dificuldade que se verificou na sua implementação.

Quanto aos electrólitos usados em células de combustível, os que meIhor contribuem para um baixo ASR são naturalmente os mais condutores, nomeadamente o hidróxido de potássio, nas células AFC, com condutividades superiores a $1 \mathrm{~S} \mathrm{~cm}^{-1}$, o ácido fosfórico nas PAFC e os electrólitos de carbonatos fundidos nas MCFCs. As membranas de Nafion usadas nas células de membrana polimérica têm condutividades bastante menores, mas, em contrapartida, são de fabrico fácil sob a forma de filmes finos, com espessuras da ordem dos $100 \mathrm{~nm}$, pelo que é possível atingir com elas valores de ASR razoáveis, desde que a quantidade de água incorporada nos filmes seja controlada nas condições dinâmicas do funcionamento das células.
Os electrólitos das célula de combustível de óxido sólido são materiais cerâmicos, bons condutores de iões $\mathrm{O}^{2-}$, a temperaturas elevadas, nomeadamente a ítria, $\mathrm{Y}_{2} \mathrm{O}_{3}$, estabilizada em zircónia, $\mathrm{ZrO}_{2}$ (YSZ), sob a forma de filmes com espessuras da ordem dos 10 a $30 \mu \mathrm{m}$. São, no entanto, de fabrico difícil, pois têm de ser sinterizados a temperaturas da ordem dos $1400^{\circ} \mathrm{C}$, sobre substratos cerâmicos porosos que, em geral, são os próprios eléctrodos. Os materiais para esse efeito têm de ser cuidadosamente escolhidos de modo a que não reajam com o electrólito durante o processo de sinterização a alta temperatura. Estas componentes em materiais cerâmicos são frágeis o que limita as aplicações deste tipo de células a situações em que não há flutuações bruscas de temperatura. Este problema tem sido objecto de investigação intensa, com desenvolvimentos recentes nos processos de sinterização a temperaturas abaixo dos $1000^{\circ} \mathrm{C}$, que permitem o uso de substratos metálicos possibilitando assim o desenvolvimento de sistemas de pilhas de combustível mais resilientes.

Outra componente importante das piIhas de combustível é a placa bipolar (Fig. 2) que, como se referiu, actuam como ânodo para uma célula e como cátodo para a célula seguinte. Podem ser de metal, carbono ou um compósito polimérico (usualmente incorporando carbono). As placas bipolares têm como funções: i) constituir uma estrutura sólida para a pilha, ii) servir de meio condutor entre o ânodo e o cátodo da célula seguinte, iii) separar os gases entre células (gases reagentes e vapor de água de exaustão), iv) distribuir o combustível e o ar para o ânodo e o cátodo respectivamente, e v) dissipar o calor para o exterior da célula. Devem portanto ter as seguintes características: i) ser impermeáveis aos gases (e.g. hidrogénio e oxigénio), ii) ter boa condutividade eléctrica, iii) ser mecanicamente resistentes e leves, especialmente para as aplicações em transportes, iv) ser resistentes à corrosão, especialmente nas condições acídicas das células de electrólito polimérico e de ácido fosfórico, o que limita a escolha do material para esses tipos de células, praticamente à grafite, v) serem de fabrico fácil em grandes quantidades. Muitos programas de investigação e desenvolvimento visam materiais alternativos à grafite, especialmente para as células de ácido fosfórico e de electrólito polimérico. Alguns desses programas têm por objectivo o desenvolvimento de materiais alternativos à base de carbono produzidos por moldagem de injecção, ou aços inoxidáveis revestidos. Para os sistemas de alta temperatura MCFC e SOFC que funcionam na gama de temperaturas dos 500 aos $750{ }^{\circ} \mathrm{C}$, podem especificar-se composições de aços inoxidáveis que satisfaçam os requisitos técnico-económicos desejados. Para sistemas de mais alta temperatura, na gama dos 800 a $1000^{\circ} \mathrm{C}$ são necessários materiais de placa bipolar mais caros o que presentemente constitui um problema.

Outros problemas que determinam a escolha de materiais para células de combustível têm que ver com a fiabilidade e a durabilidade. Para aplicações em transportes, a degradação admitida não deve exceder valores da ordem de $0,1 \%$ em 1000 horas de funcionamento, e devem manter esses valores ao longo de pelo menos 5000 h. Para aplicações estacionárias, como, por exemplo, em instalações combinadas de produção de electricidade e calor (cogeração), a taxa de degradação deve manter-se igualmente baixa por períodos da ordem da 40000 h, ou seja, cerca de 5 anos. Esta parece ser uma das limitações das pilhas de electrólito polimérico, inicialmente desenvolvidas para aplicações em transportes.

A ciência e a tecnologia de materiais é ainda de grande importância para as tecnologias de células de combustível no que respeita aos acessórios dos sistemas de pilhas, tais como bombas, válvulas, tubos e permutadores de calor, que constituem cerca de metade do custo do sistema de células, havendo ainda a considerar reformadores, quando necessários, sendo estes alvo de intensa investigação, salientando-se os recentes desenvolvimentos mais inovadores que usam componentes do tipo circuito impresso ou com microcanais para refor- 
madores compactos. Note-se que os materiais correntemente usados nas células de combustível de electrólito polimérico, (PEMFC), de carbonatos fundidos (MCFC) e protótipos de células tubulares de óxidos sólidos (SOFC) são essencialmente os mesmos de há 30 anos, embora tenha havido, sobretudo nos últimos dez anos, alguma inovação nas tecnologias de processamento e na diminuição da carga de catalisador.

Actualmente, o foco do esforço de investigação e desenvolvimento na área das células de combustível centra-se nos materiais alternativos aos actualmente usados, e na concepção e design dos sistemas, tendo sempre em conta os materiais existentes ou a desenvolver para o efeito.

No caso das PEMFC, são os materiais para as estruturas de suporte, para as placas bipolares, para os catalisadores e para a membrana condutora iónica. Quando são usados reformadores para produzir o hidrogénio a partir de outros combustíveis, há requisitos especiais para o catalisador que tem de ser resistente ao CO. O maior desafio põe-se talvez para as células de alimentação directa de metanol (DMFC), uma vez que os materiais de membrana comuns são permeáveis ao metanol, o que constitui um grave problema pois forma-se CO durante a sua electro-oxidação. Embora a grafite seja muito menos condutora do que os metais, ela é ainda um dos materiais preferidos para as placas bipolares, pela sua resistência à corrosão, sendo também usados compósitos de grafite com polímeros (e.g., polipropileno).

A utilização de metais para as placas bipolares tem a vantagem de ser mais fácil fabricar a estrutura de circulação dos gases, mas poucos metais são resistentes à corrosão no ambiente acídico das membranas. Os metais mais usados são os aços inoxidáveis passivados no lado do cátodo, havendo normalmente produtos de corrosão no lado do ânodo. Os metais alternativos como o titânio, o nióbio, o tântalo e o ouro ou metais revestidos a ouro são demasiado caros. No que respeita aos catalisadores, o material mais activo é a platina. Para reduzir os custos, usam-se nanopartículas em substratos de carbono, sendo hoje possível reduzir o teor em platina a valores da ordem de $0,5 \mathrm{mg} \mathrm{cm}^{-2}$ sem prejuízo para o desempenho e durabilidade. Nos casos em que há traços de CO nos combustíveis ou no caso das células de metanol de alimentação directa, em que o envenenamento pelo $\mathrm{CO}$ é um problema, têm sido propostas ligas de platina e ruténio com aumentos significativos do desempenho.

Um dos materiais comerciais mais comuns para membranas das células de combustível do tipo PEMFC é o $\mathrm{Na}$ fion, desenvolvido pela DuPont nos anos de 1960. O Nafion é, como já vimos, um ionómero com um esqueleto perfluorado como o Teflon, havendo, no entanto muitos outros ionómeros para membranas de permuta iónica, usando polímeros poliaromáticos ou outros parcialmente fluorados. As características essenciais da membrana são a elevada condutividade protónica, a permeabilidade ao metanol, mas impermeabilidade relativamente aos gases, e a estabilidade mecânica e térmica.

O Nafion e materiais afins são a opção mais comum para membranas em pilhas de combustível mas os seus custos são elevados, o que tem levado à procura de outros materiais mais baratos, como por exemplo alguns poliarilenos sulfonados e aductos do polibenzimidazole com ácidos inorgânicos, estes últimos para aplicações a altas temperaturas. Têm sido também tentados, sem grande sucesso, muitos outros electrólitos poliméricos semelhantes aos desenvolvidos para baterias de polímero, incluindo materiais híbridos, com uma componente inorgânica.

Nas células MCFC os pontos críticos são a corrosão e a estabilidade estrutural dos materiais enquanto que nas SOFC são a condutividade e a estabilidade estrutural.

Nas aplicações para dispositivos electrónicos portáteis, que requerem potências de $1-50 \mathrm{~W}$, as células de combustível mais apropriadas são as PEMFC alimentadas a hidrogénio e as DMFC alimentadas a metanol mas nestas é necessário melhorar as membranas de modo a diminuir a permeabilidade ao metanol e à água. Nas Micro-CHP (cogeração de electricidade e calor), com potências na gama de $1-10 \mathrm{~kW}$, as mais adequadas continuam a ser as PEMFC, mas alimentadas a metano e fuel (mistura de hidrocarbonetos) para as quais são necessários ânodos tolerantes de $\mathrm{CO}$, novos tipos de membranas e de placas bipolares.

Nas células do tipo SOFC, são as propriedades do electrólito sólido que mais influenciam a selecção dos materiais e o design das pilhas de combustível. A espessura máxima permitida para uma dada componente do electrólito depende da especificação do parâmetro ASR da pilha, que, naturalmente depende da temperatura de funcionamento. Por exemplo, uma configuração que especifique uma componente de electrólito de YSZ com uma espessura de cerca de $150 \mu \mathrm{m}$ implica uma temperatura de funcionamento superior a $950^{\circ} \mathrm{C}$, para um valor máximo da contribuição do electrólito de $0,15 \Omega \mathrm{cm}^{2}$ para o parâmetro ASR, o que coloca problemas para configurações planares, sendo, neste caso, adoptadas configurações tubulares como a adoptada pela Siemens-Westinghouse.

Essa configuração usa um cátodo tubular de $\mathrm{La}(\mathrm{Sr}) \mathrm{MnO}_{3}$ com 1,5 m. Após deposição de uma pista de $\mathrm{La}(\mathrm{Sr})$ $\mathrm{CrO}_{3}$ por plasma, segue-se a deposição da camada de YSZ com 30 a $40 \mu \mathrm{m}$ de espessura por deposição electroquímica. A estrutura da célula é finalizada depositando o ânodo de Ni-YSZ por pulverização. A escolha do material do cátodo $\mathrm{La}(\mathrm{Sr}) \mathrm{MnO}_{3} \mathrm{e}$ do ânodo Ni-YSZ foi estabelecida pela Westinghouse e ABB, nos anos de 1970 , após prolongada investigação das composições mais compatíveis a longo termo com a YSZ a temperaturas elevadas.

O desenho tubular da Siemens-Westinghouse é ainda um dos mais avançados e têm sido testadas unidades de $25 \mathrm{~kW}, 100 \mathrm{~kW}$ e $200 \mathrm{~kW}$, estas últimas recentemente combinadas com microturbinas num sistema com eficiências da ordem dos $60 \%$, sendo 
previsível chegar a eficiências próximas dos $70 \%$ em instalações de vários MW (megawatts).

Para as células SOFC de temperaturas intermédias $\left(500^{\circ} \mathrm{C}-750^{\circ} \mathrm{C}\right)$, um valor máximo de $0,15 \Omega \mathrm{cm}^{2}$ para a contribuição do ASR implica para uma camada de $15 \mu \mathrm{m}$ de espessura, uma condutividade do electrólito superior a $10^{-2} \mathrm{~S} \mathrm{~cm}^{-1}(\sigma=L / A S R=0,0015 / 0,15)$ que corresponde a uma temperatura de funcionamento de $700{ }^{\circ} \mathrm{C}$, se o electrólito for $\mathrm{YSZ}$, e de $500{ }^{\circ} \mathrm{C}$ se o electrólito for $\mathrm{Ce}_{0,9} \mathrm{Gd}_{0,1} \mathrm{O}_{1,95^{\circ}}$ É claro que o uso de camadas de electrólito mais finas possibilitaria temperaturas de funcionamento mais baixas, mas a espessura mínima que permite uma produção industrial a custos razoáveis é da ordem dos $10 \mu \mathrm{m}$, em substratos com as requeridas propriedades de resistência mecânica e permeabilidade aos gases.

Alguns fabricantes estão a apostar em placas bipolares metálicas, nomeadamente de aços ferríticos com baixo coeficiente de expansão térmica, com electrólitos de YSZ e cátodos de $\mathrm{La}(\mathrm{Sr}) \mathrm{MnO}_{3}-\mathrm{YSZ}$.

O design das pilhas de combustível é de enorme importância se se pretenderem produtos duradouros e a preços competitivos, em particular os de média potência (1-10 kW) para cogeração de electricidade e calor, e unidades de potência auxiliares, tendo sido já demonstrados custos de produção da ordem dos $700 €$ por kW. Muitos outros materiais cerâmicos condutores iónicos de $\mathrm{O}^{2-}$ têm sido estudados e propostos como electrólitos, nomeadamente materiais como $\mathrm{Ce}_{0,9} \mathrm{Gd}_{0,1} \mathrm{O}_{1,95}$ e $\mathrm{LaGaO}_{3}$ que permitem baixar a temperatura de funcionamento para cerca de $600^{\circ} \mathrm{C}$, mas apesar da intensa investigação sobre a síntese de materiais alternativos com as necessárias propriedades tem provado ser difícil competir com materiais mais tradicionais à base de céria, $\mathrm{CeO} 2$, e de zircónia, $\mathrm{ZrO}_{2}$. $\mathrm{Na}$ tabela 2 apresenta-se um resumo das aplicações mais prováveis das pilhas de combustível num futuro próximo, indicando as metas a atingir no que respeita à escolha dos materiais críticos.

Tabela 2 Aplicações das pilhas de combustível e aspectos críticos relativos aos materiais

\begin{tabular}{|c|c|c|c|c|}
\hline Aplicação & Potência/kW & Tipo de célula & Combustível & Metas a atingir \\
\hline $\begin{array}{l}\text { Sistemas de potência para } \\
\text { dispositivos electrónicos portáteis }\end{array}$ & $0,001-0,05$ & $\begin{array}{l}\text { PEMFC } \\
\text { DMFC }\end{array}$ & $\begin{array}{c}\mathrm{H}_{2} \text { Hidrogénio } \\
\mathrm{CH}_{3} \mathrm{OH} \text {, Metanol }\end{array}$ & $\begin{array}{l}\text { Membranas impermeáveis ao } \\
\text { metanol e à água }\end{array}$ \\
\hline Microcogeração & $1-10$ & $\begin{array}{l}\text { PEMFC } \\
\text { SOFC }\end{array}$ & $\begin{array}{l}\text { Hidrogénio } \\
\text { Fuel } \\
\text { Hidrogénio } \\
\text { Fuel }\end{array}$ & $\begin{array}{l}\text { Ânodos tolerantes a CO. } \\
\text { Estruturas ânodo-electrólito- } \\
\text {-cátodo de camada espessa } \\
\text { robustas a funcionar a } \\
\quad 500-700^{\circ} \mathrm{C} \text {. }\end{array}$ \\
\hline $\begin{array}{l}\text { Sistema de potência auxiliar, } \\
\text { Unidades de produção } \\
\text { ininterrupta, locais remotos. }\end{array}$ & $1-10$ & SOFC & $\begin{array}{c}\text { Fuel } \\
\text { Gasolina }\end{array}$ & $\begin{array}{l}\text { Estruturas ânodo-electrólito- } \\
\text {-cátodo de camada espessa } \\
\text { robustas a funcionar a } \\
500-700^{\circ} \mathrm{C} . \\
\text { Arranque rápido. }\end{array}$ \\
\hline $\begin{array}{c}\text { Cogeração de electricidade e } \\
\text { calor }\end{array}$ & $50-250$ & $\begin{array}{l}\text { PEMFC } \\
\text { MCFC } \\
\text { SOFC }\end{array}$ & $\begin{array}{l}\text { Metano } \\
\text { Metano } \\
\text { Metano }\end{array}$ & $\begin{array}{l}\text { Ânodos tolerantes a CO. } \\
\text { Melhores materiais de } \\
\text { eléctrodos e com melhores } \\
\text { características de ciclos } \\
\text { térmicos. } \\
\text { Processos de fabrico mais } \\
\text { baratos. } \\
\text { Ânodos resistentes a } \\
\text { processos redox. } \\
\text { Materiais cerâmicos mais } \\
\text { condutores e mais estáveis. }\end{array}$ \\
\hline Autocarros de cidade & 200 & PEMFC & Hidrogénio & Componentes mais baratas. \\
\hline Unidades de alta potência & $1000-10000$ & SOFC & Metano & $\begin{array}{c}\text { Processos de fabrico mais } \\
\text { baratos para sistemas } \\
\text { tubulares. }\end{array}$ \\
\hline
\end{tabular}




\section{Conclusão}

Os custos de investimento correntes em pilhas de combustível protótipo são nitidamente demasiado elevados (da ordem de $2000-6000 € / \mathrm{kW}$ ), embora seja previsível a sua redução se a comparticipação no mercado, em competição com as tecnologias de produção de energia estabelecidas, justificar a produção em massa. Embora já existam pequenos nichos de mercado, como por exemplo relativamente às pilhas PEMFC, para autocarros de cidade, muitos analistas consideram que seria mais prudente visar sectores de mercado de pilhas de combustível na gama dos 1 - $10 \mathrm{~kW}$, para os quais existem boas perspectivas de desenvolvimento e implementação. Essa estratégia foi a adoptada pelo departamento de Energia dos Estados Unidos da América do Norte (DOE) com a "Solid State Energy Conversion Alliance" que visa a produção em massa de pilhas SOFC de $5 \mathrm{~kW}$ a preços de cerca de $300 €$ por kW. Se a iniciativa for bem sucedida, será possível penetrar outros sectores do mercado com a mesma tecnologia.

Um dos nichos que actualmente mais está a atrair as atenções é o das piIhas de combustível para dispositivos electrónicos portáteis. Na medida em que as baterias lutam para satisfazer as especificações cada vez mais exigentes, as pilhas de metanol de alimentação directa (DMFCs) com concepções e design inovadores baseadas nas tecnologias de semicondutores, prometem densidades de energia 3 a 5 vezes superiores às das actuais baterias de ião lítio. As especificações de potência relativamente baixas dos telemóveis (cerca de $1 \mathrm{~W}$ ), por exemplo, poderão levar a uma participação considerável no mercado para estas pequenas pilhas de combustível.

Note-se, no entanto, que embora haja um número considerável, em valor absoluto, de fabricantes de pilhas de combustível, a penetração no mercado é extremamente pequena. Em termos de comparticipação no mercado global de energia, o seu valor é insignificante. Na tabela 3 dão-se alguns exemplos de pilhas comercias para diversas aplicações com indicação de fabricantes.

Tabela 3 Exemplos de produtos comerciais e fabricantes

\begin{tabular}{|c|c|c|c|c|}
\hline $\begin{array}{l}\text { Tipo de } \\
\text { pilha }\end{array}$ & Combustível & Potência/kW & Aplicação & Fabricante \\
\hline AFC & Hidrogénio & $0,5-2,8$ & & ZeTek (ZeGen) \\
\hline \multirow{5}{*}{ PEMFC } & $\begin{array}{l}\text { Hidrogénio, gás } \\
\text { natural, propano, } \\
\text { biogás }\end{array}$ & $\begin{array}{l}1-10 \\
250\end{array}$ & $\begin{array}{c}\text { Residencial } \\
\text { Industrial e serviços }\end{array}$ & $\begin{array}{l}\text { Ballard Power } \\
\text { Sistems }\end{array}$ \\
\hline & $\begin{array}{l}\text { Gás natural, } \\
\text { propano }\end{array}$ & $0,25-5$ & Residencial & H-Power \\
\hline & $\begin{array}{c}\text { Gás natural, } \\
\text { propano }\end{array}$ & $0,5-200$ & $\begin{array}{l}\text { Residencial, } \\
\text { serviços }\end{array}$ & Toshiba \\
\hline & Gás natural & 7 & Residencial & Plug Power / GE \\
\hline & $\begin{array}{l}\text { Gás natural, } \\
\text { propano }\end{array}$ & $5-10$ & $\begin{array}{l}\text { Residencial, } \\
\text { serviços }\end{array}$ & IFC - ONSI \\
\hline \multirow{2}{*}{ PAFC } & Gás natural & 200 (cogen) & \multirow{2}{*}{$\begin{array}{c}\text { Residencial, } \\
\text { serviços, industrial }\end{array}$} & \multirow{2}{*}{$\begin{array}{l}\text { CCL (IFC-ONSI/ } \\
\text { Ansaldo) }\end{array}$} \\
\hline & Hidrogénio & 200,850 & & \\
\hline \multirow{2}{*}{ MCFC } & & $\begin{array}{l}300,1500 \\
3000\end{array}$ & $\begin{array}{c}\text { Residencial, } \\
\text { serviços, industrial }\end{array}$ & FuelCell Energy \\
\hline & Gás natural, biogás & $300-10000$ & $\begin{array}{l}\text { Cogeração } \\
\text { industrial }\end{array}$ & MTU \\
\hline \multirow{3}{*}{ SOFC } & $\begin{array}{l}\text { Gás natural, } \\
\text { propano }\end{array}$ & $1-25$ & $\begin{array}{l}\text { Residencial, } \\
\text { industrial }\end{array}$ & $\begin{array}{c}\text { Global } \\
\text { Thermoelectric }\end{array}$ \\
\hline & Gás natural & $250-1000$ & Industrial & $\begin{array}{c}\text { Siemens } \\
\text { Westighouse }\end{array}$ \\
\hline & Gás natural & $1-?$ & Residencial & Sulzer Hexis \\
\hline
\end{tabular}

\section{Bibliografia}

- Linda Carrette, K. Andreas Friedrich and Ulrich Stimming, "Fuel cells: Principles, Types, Fuels and Applications", ChemPhysChem 1 (2000) 162.

- M. S. Dresselhaus and I. L. Thomas, "Alternative energy technologies", $\mathrm{Na}$ ture 414 (2001) 332.

- Brian C. H. Steele and Angelika Heinzel, "Materials for fuel-cell technologies", Nature 414 (2001) 345.

- Günter Hörmandinger and Nigel J. D. Lucas, "An Evaluation of the Economics of Fuel Cells in Urban Buses", International Journal of Energy Research 21 (1997) 495.
- Centro de Estudos em Economia da Energia, dos Transportes e do Ambiente, CEEETA, "Tecnologias de MicroGeração e Sistemas Periféricos - PiIhas combustivel", Dezembro $2001 \Rightarrow$ http://www.scribd.com/doc/7784171/ Pilhas-combustivel

Informação sobre produtos e mercados de pilhas de combustível para sistemas de potência estacionários, militares, transportes, portáteis de média dimensão e micropotência para dispositivos electrónicos pode ser encontrada no seguinte site: http://www.fuelcellmarkets.com/fuel_cell_ markets/1,1,1.html 
Most accessed articles

9/2006-8/2007

Cu'-Catalyzed Alkyne-Azide "Click" Cycloadditions from a Mechanistic and Synthetic Perspective

V. D. Bock, H. Hiemstra,

J. H. van Maarseveen

Eur. J. Org. Chem. 2006, pp. 51-68

Recent Advances in Asymmetric

Organocatalytic 1,4-Conjugate Additions

S. B. Tsogoeva

Eur. J. Org. Chem. 2007, pp. 1701-1716

Asymmetric Ring-Opening of Epoxides and Aziridines with Carbon Nucleophiles M. Pineschi

Eur. J. Org. Chem. 2006, pp. 4979-4988

Gold-Catalyzed Hydroamination of C-C Multiple Bonds

R. A. Widenhoefer, X. Han

Eur. J. Org. Chem. 2006, pp. 4555-4563

Organocatalytic Synthesis of Drugs and Bioactive Natural Products

R. M. de Figueiredo, M. Christmann

Eur. J. Org. Chem. 2007, pp. 2575-2600

Articles were downloaded ca. 500,000

times in the last 12 months by scientists in over 120 countries. EurJOC is among the top ten most frequently visited journals in Wiley InterScience.
For more information please visit: www.eurjoc.org

\section{Subscribe now!}

Please send an e-mail to:

cs-journals@wiley.com

(North and South America)

service@wiley-vch.de

(Germany/Austria/Switzerland)

cs-journals@wiley.co.uk

(all other areas)

\section{WWILEY}

InterScience

(2)WILEY-VCH

\section{Made in Europe for the World}

\section{Geographical distribution of published articles 2006}

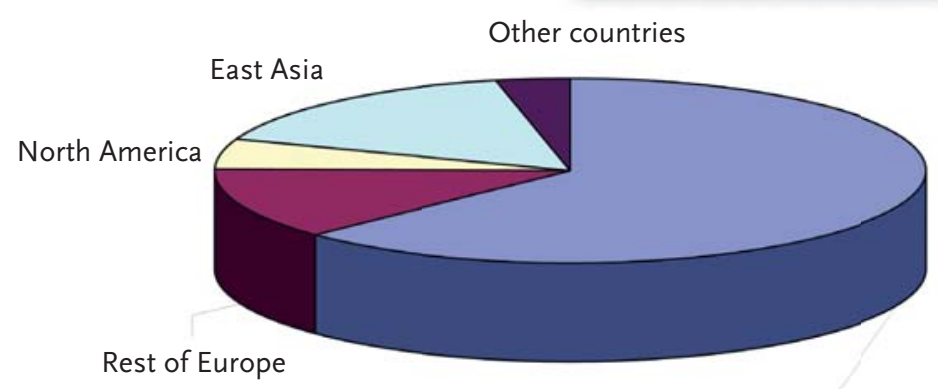

EUChemSoc partner countries

\section{Manuscripts received 2001-2006}

Since 2002, EurJOC has seen an average yearly increase of $11 \%$ in manuscripts submitted.

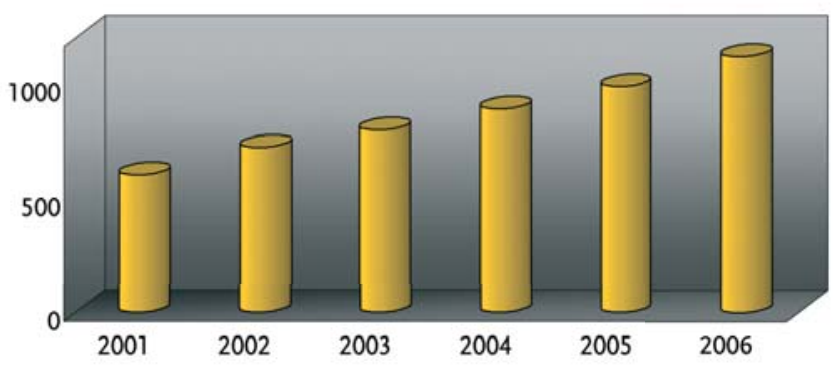

\section{EurJOC Facts}

ISI Impact Factor (2006): 2.769

EurJOC ranks 18th of 56 journals included in the category "Chemistry, Organic" in the Journal Citation Reports ${ }^{\circledR}$ (ISI Web of Knowledge ${ }^{S M}$ ). The Median Impact Factor in this category is 1.894 and the Aggregate Impact Factor is 2.564.

- Increased frequency in 2007: 36 Issues

- Owned and supported by the 13 national chemical societies of EUChemSoc (Editorial Union of Chemical Societies)

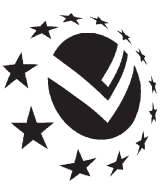

EUChemSoc

\section{EurJOC offers:}

- 1 RSS Feeds: be automatically informed of new articles as soon as they are published online in EarlyView

- Citation tracking

- Backfiles (Liebigs Annalen 1832-1997)

- Attractive personal subscription rates for society members 


\section{Actualidades Científicas}

\section{Perspectivas de forte inVestimento NA ELECTRICIDADE SOLAR}

A ideia de construir instalações de geração solar de electricidade no deserto do Sara não é nova, mas é reconhecidamente difícil de implementar e, acima de tudo, muito dispendiosa. $A$ construção de uma área de recolha do tamanho da Áustria chegaria para satisfazer as necessidades mundiais de electricidade. Será contudo necessário construir linhas de transporte para a Europa. Apesar do custo, trata-se de uma tecnologia sem produção de dióxido de carbono, e, por isso, merecedora de uma atenção cuidada.

\section{A Munich Re (ou Munich Reinsurance} Company), a maior companhia seguradora do mundo, pretende promover a criação de um consórcio (Desertec) que, reunindo grandes companhias (como a Siemens, o Deutsche Bank, e os fornecedores de energia RWE e E.ON), possa implementar a construção de estações de energia solar em África e Arábia e ligá-las à Europa. O objectivo é ajudar a combater o aquecimento global, dado que este influencia a ocorrência de catástrofes naturais com implicações directas nos negócias das empresas de seguros, na actividade económica em geral e, no limite, na própria sustentabilidade das sociedades humanas.

As estações solares seriam do tipo solar-térmica em vez de fotovoltaica. Ou seja, em vez de converter a eneria solar directamente em energia eléctrica, a energia solar seria concentrada, com espelhos, em caldeiras para a produção de vapor que accionaria turbinas ou em contentores com sais especiais de baixa temperatura de fusão que armazenariam o calor durante a noite, ficando assim disponível para accionar as turbinas durante a noite. Este investimento de larga escala poderá ainda estimular a inovação e reduzir os custos da electricidade solar. De momento nenhuma forma solar de geração de electricidade é tão barata quanto a produção eléctrica a partir de carvão. Contudo, a produção solar-térmica é apontada por muitos como uma aposta melhor do que a fo- tovoltaica. A implementação deste esquema pode envolver investimentos da ordem de 400 mil milhões de euros nos próximos 40 anos. Tal permitiria a construção de estações solares necessárias para satisfazer $15 \%$ das necessidades da Europa e as necessidades da maior parte dos países do Norte de África e da Arábia em 2050 e cerca de 20 linhas transnacionais de distribuição. É uma proposta extraordinariamente ambiciosa mas não disparatada.

(Adaptado de The Economist de 8 de Julho de 2009)

\section{Novas ABORdagens PARA PRODUÇÃo DE ENERGIA SOLAR}

O silício é o material dominante no fabrico de painéis fotovoltaicos. Apesar da abundância de areia, o fabrico de silício é dispendioso, o que encarece o produto final. Por isso, os esforços para reduzir o grau de incorporação de silício e, assim, o custo final dos painéis fotovoltaicos podem ser relevantes para a sustentabilidade desta tecnologia em aplicações de larga escala. Os painéis solares são habitualmente constituídos por finas camadas de silício recobertas por placas de vidro. Cientistas na empresa israelita GreenSun Energy propõem-se utilizar menos silício, utilizando apenas silício a recobrir as faces laterais das placas de vidro. Para tal, a luz que incide nas placas de vidro é difundida para as paredes laterais onde ocorre a sua conversão em energia eléctrica pelo silício aí colocado. O vidro é recoberto com uma combinação de corantes e "salpicado" com nanopartículas metálicas, cuja natureza não é divulgada. Os corantes usados são fluorescentes, absorvendo a luz incidente e re-emitindo luz a maior comprimento de onda. A utilização de uma mistura de corantes permite absorver todas as partes do espectro. As nanopartículas metálicas desempenham um papel mais subtil: a luz re-emitida pelos corantes é convertida numa outra forma de radiação electromagnética, designada por plasmões superficiais. Estes propagam-se à superfície do vidro até que são absorvidos pelo silício colocado nas paredes laterais. Este processo promete, além da redução de custo, aumentar a eficiência dos painéis fotovoltaicos. Num painel convencional, muita da energia incidente é perdida, dado que a energia dos fotões que excede a quantidade necessária para criar carga é convertida em calor. A mistura de corantes/nanopartículas metálicas permite converter e conduzir até ao silício a energia adequada para criar cargas eléctricas, eliminando as perdas sob a forma de calor. O custo da energia fotovoltaica é, actualmente, cerca de 5 vezes o da electricidade disponível na rede de distribuição. Esta nova tecnologia pode permitir, no estágio de desenvolvimento actual, produzir energia eléctrica custando apenas o dobro da energia produzida nas instalações convencionais. A empresa espera poder aumentar a eficiência e reduzir os custos de forma a torná-los idênticos aos da electricidade da rede.

Uma outra empresa israelita, 3GSolar, espera poder prescindir totalmente do silício. Esta empresa trabalha com células sensibilizadas por corante ou células de Grätzel, inventadas há cerca de 20 anos. Estas células usam dióxido de titânio e moléculas de corantes complicadas, como complexos de ruténio. A $3 G$ solar está a trabalhar neste tipo de células que prometem ser mais baratas do que as células fotovoltaicas de silício e de células fabricadas com outros semicondutores inorgânicos (como telureto de cádmio). Embora sejam menos eficientes, o seu baixo custo pode torná-las competitivas para algumas aplicações. Estes tipos de células competem ainda com as células orgânicas de filme fino, que usam polímeros e outras moléculas de baixo peso molecular e que podem ser fabricadas a partir dos componentes em solução, mas cuja eficiência é também inferior às de silício.

Esta é uma área de enorme actividade, que beneficia das crescentes preocupações sobre sustentabilidade e desenvolvimento sustentável e dos tão propalados efeito de estufa e aquecimento global.

(Adaptado de The Economist de 23 de Julho de 2009) 


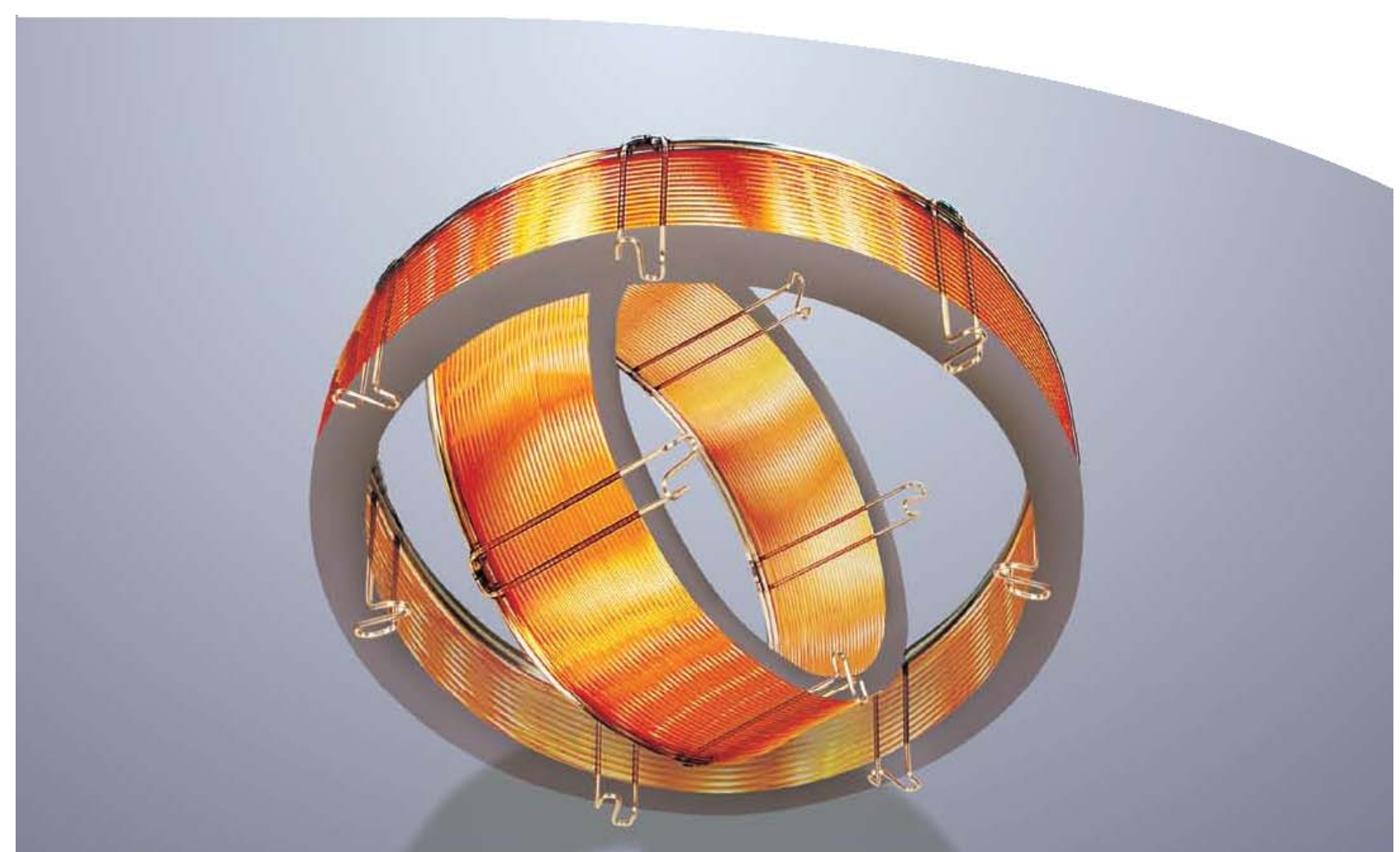

\section{Innovation Comes In Many forms}

Zebron - Revolutionizing the Field of Gas Chromatography

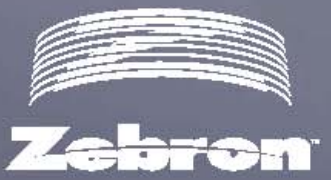

\begin{tabular}{|c|c|}
\hline Zebron "ZB-WAXPLUS: & Ideal for polar compounds. $100 \%$ aqueous stable \\
\hline Zebron MultiResidue & $\begin{array}{l}\text { Perfect for pesticide analysis. For US EPA } 8081 \mathrm{~A} \text {, } \\
\text { baseline resolution is achieved in just } 10 \text { minutes! }\end{array}$ \\
\hline $\begin{array}{l}\text { Zebron ZB-1HT Inferno"' } \\
\text { and ZB-5HT Inferno }\end{array}$ & $\begin{array}{l}\text { The world's highest temperature non-metal GC } \\
\text { columns. Provides true boiling point separation } \\
\text { for hydrocarbon distillation methods. }\end{array}$ \\
\hline
\end{tabular}

Zebron has been revolutionizing the field of gas chromatography with its oommitment to producing innovative, high quality oolumns that meet the needs of today's gas chromatographers. Our scientists have developed key technologies, such as Engineered Self Cross-linking"' (ESC) and Arylene Matrix Technology"' (AMT), to oreate GC columns that provide high temperature stability, improved lifetime, low bleed, and low activity. Each and every column is individually $Q C$ tested to ensure that they have excellent batoh-to-batch reproducibility so you will have reliable and reproducible results, eveny time. For a column that best meet your needs, please contaot your local Phenomenex Technical Specialist

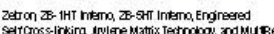

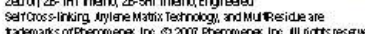

$[\oplus]=$

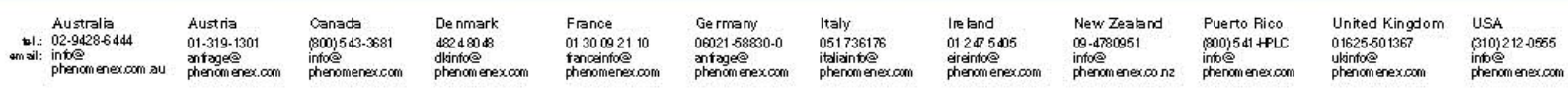

